\title{
Public health experts urge realistic pot laws
}

$\mathrm{N}$ ew Canadian laws to legalize marijuana need to balance harm reduction with pragmatism, say public health experts.

The Canadian Public Health Association (CPHA) is urging the federal government to introduce tight upstream controls on production, retail sales and marketing of legal marijuana. At the same time, Canada must not be too prohibitive when it comes to access or use of the drug or people will return to the illegal market.

"It's the first time we've ever been able to create a regulatory system from the ground up, so let's get it right," says Ian Culbert, the association's executive director.

CPHA brought together about 100 public health professionals in June to hammer out what getting it right might look like. Based on those discussions, the association made a submission to the federal Task Force on Marijuana Legalization and Regulation on Aug. 29 calling for a single, nationally consistent system to regulate both recreational and medical cannabis. CPHA also advised the government to maintain the current for-profit medical marijuana production system to meet new demand.

However, that should be the full extent of involvement by for-profit companies, Culbert says. "Commercial interests shouldn't be involved in retail sales."

CPHA is urging the government to avoid compromises made in tobacco and alcohol regulation and start strong by prohibiting advertising, requiring plain packaging and health warning labels, limiting the strength of pot products, and banning those that might be attractive to children, such as cannabis candies.

Ideally, sales should be conducted online and products delivered by mail, as is currently the case for medical marijuana. "It's proven to be extremely effective, safe and efficient," says Culbert.

CPHA also proposes that any brickand-mortar stores should be run by the government or a nonprofit organization that emphasizes education and harm reduction over sales. For the same reason, cannabis shouldn't be sold alongside alcohol or in pharmacies, Culbert explains. "You're sending the message that the products should be consumed

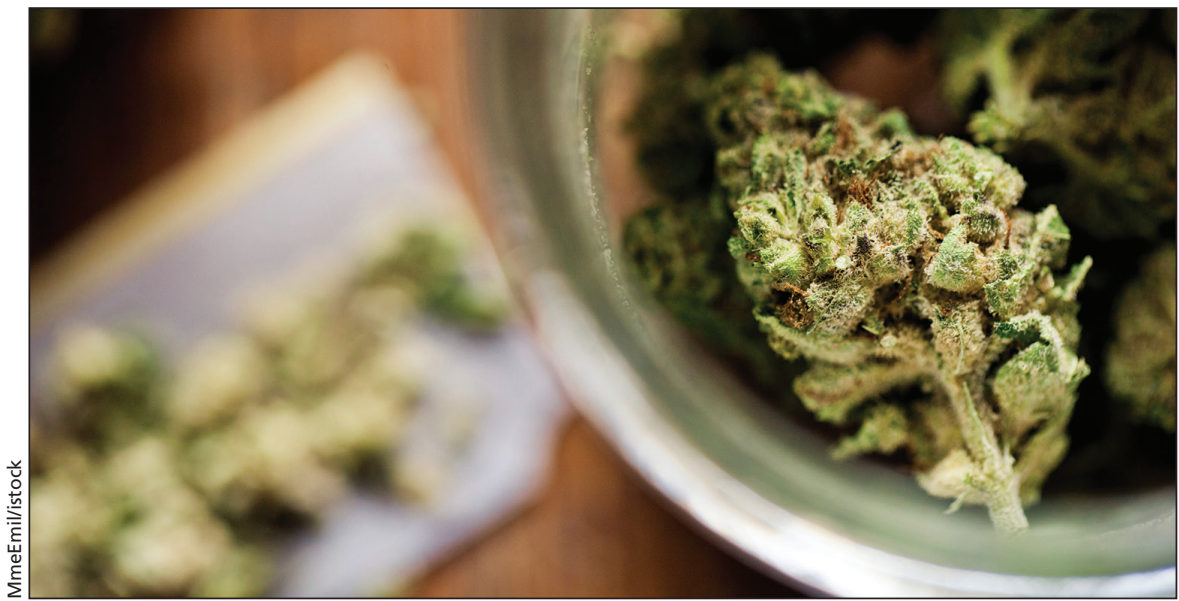

The Canadian Public Health Association is warning government not to allow commercial interests to drive recreational marijuana sales.

together and if you look at most government-run liquor stores - the [Liquor Control Board of Ontario], for example - they actively engage in promoting consumption."

The challenge facing lawmakers will be balancing these restrictions to prevent harm with sufficient access to woo people from the illegal market. According to a $2015 C M A J$ analysis (www.cmaj.ca/ lookup/doi/10.1503/cmaj.150657), Canada should follow the example of jurisdictions that used evidence, not ideology, to guide cannabis policies.

Lewis Koski, who oversees marijuana enforcement in Colorado, argues that there's no point introducing a law that no one will follow. "We really want to pride ourselves and measure success in higher compliance, not how much we make in fines or how many people we arrest," he said at a recent meeting in Toronto on the future of drug policy in Canada.

At the same meeting, public health experts debated realistic age limits for marijuana given current evidence of harm to the developing brain up to age 25 . Jenna Valleriani, a strategic adviser for Canadian Students for Sensible Drug Policy, argued that age limits should reflect when a person is old enough to make reasonable decisions, not when those substances are safe. "Restrictions can be very important, but they won't stop young people from using cannabis," she said.

Portugal's National Drugs Coordinator Dr. João Castel-Branco Goulão noted that decriminalization of all drugs in 2001 allowed his country to refocus on harm prevention and addiction treatment, while freeing up police resources to hunt criminal "big sharks." Portugal has since seen a drop in injection drug use, opiate-related deaths and infectious diseases, as well as burden on the criminal justice system, Goulão said.

Canadian doctors are divided about how permissive new marijuana rules should be. A recent Canadian Medical Association survey shows just over half $(51.7 \%)$ oppose allowing cannabis use in public spaces. Many preferred setting the minimum age for purchase at 21 or $25(45.7 \%)$.

CPHA, for its part, recommends that government set a national age limit at 19 - "a happy medium," says Culbert.

The association is also encouraging government to regulate public use of marijuana under the same smoke-free bylaws that govern tobacco.

"It's unrealistic to completely forbid any consumption in any public space," Culbert explains. "If a homeless person wants to smoke cannabis, where can they do it if it's banned everywhere? Are you going to criminalize that person because they don't have a home?"

The federal Task Force on Marijuana Legalization and Regulation concluded an online public consultation on Aug. 29 and will deliver a report to Parliament in November. - Lauren Vogel, CMAJ

CMAJ 2016. DOI:10.1503/cmaj.109-5329 